\title{
Gender-related differences in morbidity and mortality during combined valve and coronary surgery
}

\author{
Mohamed F. Ibrahim, FRCS(C-Th) ${ }^{\mathrm{a}}$ \\ Domenico Paparella, MD ${ }^{\mathrm{a}}$ \\ Joan Ivanov, $\mathrm{PhD}^{\mathrm{a}}$ \\ Michael R. Buchanan, $\mathrm{PhD}^{\mathrm{b}}$ \\ Stephanie J. Brister, MD ${ }^{\mathrm{a}}$
}

See related articles on pages $929,932,936$, and 950 .
From the Division of Cardiovascular Surgery of Toronto General Hospital and University of Toronto, ${ }^{\text {a }}$ Toronto, Ontario, Canada, and the Department of Pathology and Molecular Medicine, McMaster University Health Sciences Centre, ${ }^{\text {b }}$ Hamilton, Ontario, Canada.

Received for publication Dec 10, 2001; revisions requested Jan 23, 2002; revisions received Nov 8, 2002; accepted for publication Nov 25, 2002.

Address for reprints: Stephanie J. Brister, MD, Toronto General Hospital, University Health Network, 200 Elizabeth St, 14 Eaton North, Room 214, Toronto, Ontario M5G 2C4, Canada (E-mail: stephanie.brister@ uhn.on.ca).

J Thorac Cardiovasc Surg 2003;126:959-64

Copyright $\odot 2003$ by The American Association for Thoracic Surgery

$0022-5223 / 2003 \$ 30.00+0$

doi:10.1016/S0022-5223(03)00355-6
Background: Gender-related differences in morbidity and mortality are well described for coronary artery bypass grafting but are not well understood for combined valve and bypass surgery.

Methods: We reviewed retrospectively the morbidity and mortality of 1570 consecutive patients who underwent combined valve and bypass procedures at the Toronto General Hospital between January 1990 and October 2000.

Results: There were 1073 men (68\%) and 497 women (32\%). The mean ages ( \pm 1 SD) of women and men were $69 \pm 9$ and $68 \pm 9$ years, respectively $(P=.02)$. Of the 1570 total patients, 973 patients $(62 \%)$ underwent aortic valve and coronary bypass surgery , 481 patients $(31 \%)$ had mitral valve and coronary bypass operations, and $116(7 \%)$ patients had double or triple valve and coronary bypass operations. Preoperative hypertension $(P=.002)$, diabetes $(P=.001)$, and atrial fibrillation $(P=.001)$ were seen more frequently in women. Body surface area was significantly lower in women $(P=.0001)$. At presentation, more women were in congestive heart failure $(69 \%$ vs $58 \%, P=.001)$ and in New York Heart Association functional class III or IV $(25 \%$ vs $19 \%, P=.001)$. Although there was no difference in the number of women with three or more diseased vessels $(32 \%$ vs $38 \%$ ), only $35 \%$ of women received three or more grafts compared with $44 \%$ of men $(P=.001)$. The use of left internal thoracic grafts, although uncommon in the whole study population (36\%), was less common in women than in men $(26 \%$ vs $41 \%, P$ $=.001)$. Multivariable logistic analyses for morbidity and mortality showed female gender to be an independent risk factor. Mitral valve replacement, age, left ventricular dysfunction, New York Heart Association classes III and IV, and association of tricuspid valve disease, diabetes, peripheral vascular disease, and preoperative renal failure were found to be independent risk factors for mortality.

Conclusion: Female gender is an independent risk factor for combined morbidity and mortality during and after combined valve and coronary bypass surgery. As with isolated coronary artery bypass grafting, women undergoing combined procedures have more premorbid conditions, are more often in heart failure, had an equal incidence of triple vessel disease but received fewer grafts than men, and, therefore, were more frequently incompletely revascularized.

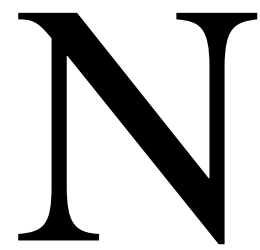

umerous studies have reported the morbidity and mortality results of mitral and/or aortic valve operations in combination with coronary artery bypass grafting (CABG) ${ }^{1-7}$ However, the risk factors influencing the early and late outcomes of valve surgery combined with CABG (V/CABG) are not clearly defined. Additionally, the impact of gender as an independent risk factor for morbidity and mortality after V/CABG is unknown. Most studies examining iso- 
lated CABG indicate that morbidity and mortality is higher for women than men. ${ }^{8-11}$ Thus, gender may be an independent risk factor for morbidity and mortality after V/CABG surgery. The present study is a retrospective descriptive analysis undertaken to examine gender as a risk factor for morbidity and mortality during and after combined V/CABG.

\section{Materials and Methods}

All data were prospectively collected for 1570 consecutive patients undergoing V/CABG at Toronto General Hospital between January 1990 and October 2000. These data are part of a computerized data registry of all cardiac surgical patients at the Toronto General Hospital.

\section{Laboratory Investigations}

Cardiac catheterization was performed in all patients over 40 years old to assess ventricular function and the extent of coronary artery disease. The left ventricular (LV) ejection fraction was estimated by a single-plane ventriculogram and graded on a scale of 1 to 4 (1 $=>60 \% ; 2=40 \%-60 \% ; 3=20 \%-40 \%$; and $4=<20 \%$ ). Coronary artery narrowing of $>50 \%$ was considered significant.

\section{Operative Technique}

Fentanyl citrate was used for induction and maintenance of anesthesia. Cardiopulmonary bypass (CPB) was established in all cases with mild hypothermia $\left(34^{\circ} \mathrm{C}\right)$. Myocardial protection was achieved with cold potassium blood cardioplegia (8:1) and a terminal hot shot in all cases. Distal anastomoses were constructed first, followed by replacement or repair of valve(s). The proximal anastomoses were performed after closure of the cardiac chambers. The left internal thoracic artery (LITA) and saphenous veins were used as conduits for CABG. Pharmacologic or mechanical support was initiated during weaning from $\mathrm{CPB}$ according to standard clinical practice. All patients were admitted to the intensive care unit postoperatively, and then transferred to the ward when their hemodynamic and respiratory functions were stable.

\section{Preoperative Variables}

Preoperative data that were collected included the following: age, gender, associated diseases such as diabetes mellitus, dialysisdependent and nondependent renal failure, previous cardiac operations, New York Heart Association (NYHA) functional class, extent and symptoms of coronary artery disease, LV ejection fraction, and cardiac rhythm.

\section{Perioperative and In-hospital Postoperative Variables}

The type of valve prosthesis or reconstruction, type of conduit, number and site of distal anastomoses, aortic crossclamp time, and duration of $\mathrm{CPB}$ were recorded as operative variables. Low cardiac output syndrome was diagnosed when the cardiac index was less than $2 \mathrm{~L} \cdot \min ^{-1} \cdot \mathrm{m}^{-2}$ and inotropic support (pharmacologic or mechanical) was needed for longer than 20 minutes. Other postoperative complications (death, myocardial infarction [MI], bleeding, cerebrovascular accident, renal failure, sepsis, and wound infection) that occurred during the hospital stay were recorded.

\section{Outcomes}

The primary outcome, hospital mortality, was defined as any in-hospital death after surgery. Secondary outcome was defined as combined morbidity and mortality.

\section{Statistical Methods}

SAS Statistical Software 6.12 was used for all statistical analyses (SAS Institute, Inc, Cary, NC). Continuous variables are reported as the mean $\pm \mathrm{SD}$ in the tables and text. Gender comparisons were made by $t$ tests for continuous variables and by $\chi^{2}$ or the Fisher exact test for categorical variables. The independent, multivariable predictors of outcome were determined by stepwise logistic regression analysis using methods previously reported. ${ }^{12}$

\section{Results}

Preoperative clinical characteristics are presented in Table 1. There were a total of 1570 patients in the study population, consisting of 1073 men $(68 \%)$ and 497 women $(32 \%)$. The women were older than the men.

Of the total patients, $62 \%$ underwent an aortic valve and CABG procedure, $31 \%$ a mitral valve and $\mathrm{CABG}$ procedure, and $7 \%$ a double valve and $\mathrm{CABG}$ procedure. Additionally, $13 \%$ of both men and women had had previous cardiac operations. Body surface area (BSA) was lower in women than in men $\left(1.7 \pm 0.2 \mathrm{~m}^{2}\right.$ vs $1.9 \pm 0.2 \mathrm{~m}^{2}, P=$ $.0001)$. Preoperative hypertension and diabetes mellitus were more prevalent in women than in men. Women also more frequently had a history of preoperative thromboembolism in the form of transient ischemic attacks and strokes than men. There was no significant difference in the prevalence of preoperative renal failure, peripheral vascular disease, and chronic obstructive airway disease between men and women.

More women had congestive heart failure. The majority of patients of both sexes $(83 \%)$ were in NYHA classes III and IV, but there was a gender-related difference with women tending to be more symptomatic. Unstable angina was present in $25 \%$ of women and $19 \%$ of men. Preoperative atrial fibrillation was more frequent in women. There was no gender-related difference in the number of diseased arteries, the proportion of patients with triple vessel disease, or the incidence of left main coronary artery disease. Similarly, LV ejection fraction was comparable between men and women.

\section{Operative Findings}

The operative characteristics of patients are shown in Table 2. There were no differences in CPB or clamp time between women and men. However, more women had urgent or emergency operations than men. Although the number of stenosed coronary arteries was equal between the sexes, and the proportion of patients with triple vessel disease was the same, women received fewer grafts than men. The use of 
TABLE 1. Preoperative clinical parameters of patients undergoing combined valve and coronary artery bypass grafting between January 1990 and October 2000 at the Toronto General Hospital

\begin{tabular}{|c|c|c|c|c|}
\hline Parameter & Female & Male & Total & $P$ value \\
\hline Patients & $497(32 \%)$ & $1073(68 \%)$ & $1570(100 \%)$ & \\
\hline $\begin{array}{l}\text { Age (years } \pm \text { SD) } \\
\text { BSA }\left(\mathrm{m}^{2}\right)\end{array}$ & $\begin{array}{c}69 \pm 9 \\
1.68 \pm 0.20\end{array}$ & $\begin{array}{c}68 \pm 9 \\
1.93 \pm 0.20\end{array}$ & & $\begin{array}{l}.02 \\
.0001\end{array}$ \\
\hline Hypertension & $278(56 \%)$ & $509(48 \%)$ & $787(50 \%)$ & .002 \\
\hline Diabetes & $129(26 \%)$ & $188(18 \%)$ & $317(20 \%)$ & .001 \\
\hline PVD & $71(14 \%)$ & $140(13 \%)$ & $211(13 \%)$ & NS \\
\hline Renal failure & $13(2.62 \%)$ & $37(3.5 \%)$ & $50(3.18 \%)$ & NS \\
\hline TIA/stroke & $85(17 \%)$ & $124(12 \%)$ & $209(13 \%)$ & .003 \\
\hline COPD & $22(4.43 \%)$ & $49(4.6 \%)$ & $71(4.52 \%)$ & NS \\
\hline $\mathrm{AF}$ & $109(22 \%)$ & $136(13 \%)$ & $245(16 \%)$ & .002 \\
\hline $\mathrm{CHF}$ & $341(69 \%)$ & $624(58 \%)$ & $965(62 \%)$ & .001 \\
\hline NYHA I & $7(1.4 \%)$ & $17(1.59 \%)$ & $24(1.5 \%)$ & NS \\
\hline NYHA II & $47(9.5 \%)$ & $183(17 \%)$ & $230(15 \%)$ & .001 \\
\hline NYHA III & $231(46 \%)$ & $498(46 \%)$ & $729(46 \%)$ & NS \\
\hline NYHA IV & $212(43 \%)$ & $374(35 \%)$ & $586(37 \%)$ & .001 \\
\hline Angina & & & & .001 \\
\hline None & $145(29 \%)$ & $247(23 \%)$ & $392(25 \%)$ & \\
\hline Stable & $225(45 \%)$ & $518(48 \%)$ & $743(47 \%)$ & \\
\hline Unstable & $127(25 \%)$ & $291(19 \%)$ & $433(19 \%)$ & .001 \\
\hline $\mathrm{MI}$ & $39(7.9 \%)$ & $73(7.8 \%)$ & $112(7.1 \%)$ & NS \\
\hline Coronary artery disease & & & & NS \\
\hline$\leq 3$ & $299(67.9 \%)$ & $652(62.3 \%)$ & $867(63.5 \%)$ & \\
\hline$\geq 3$ & $158(32 \%)$ & $411(38 \%)$ & $569(36 \%)$ & \\
\hline LMS & $53(11 \%)$ & $145(14 \%)$ & $198(13 \%)$ & NS \\
\hline Prior operation & $70(14 \%)$ & $137(13 \%)$ & $207(13 \%)$ & NS \\
\hline AV disease & & & & .001 \\
\hline Stenosis & $194(73 \%)$ & $466(67 \%)$ & $660(69 \%)$ & \\
\hline Regurgitation & $119(12 \%)$ & $88(13 \%)$ & $119(12 \%)$ & \\
\hline Mixed & $182(19 \%)$ & $137(20 \%)$ & $182(19 \%)$ & \\
\hline AV pathology & & & & .001 \\
\hline Rheumatic & $15(6 \%)$ & $20(3 \%)$ & $35(4 \%)$ & \\
\hline Tricusp/calc & $160(62 \%)$ & $389(60 \%)$ & $549(61 \%)$ & \\
\hline Bicuspid & $47(18 \%)$ & $175(27 \%)$ & $222(25 \%)$ & \\
\hline Other & $53(14 \%)$ & $114(10 \%)$ & $167(10 \%)$ & \\
\hline MV disease & & & & .001 \\
\hline Stenosis & $41(8.3 \%)$ & $22(2.05 \%)$ & $63(4.03 \%)$ & \\
\hline Regurgitation & $134(27 \%)$ & $306(29 \%)$ & $440(28 \%)$ & \\
\hline Mixed & $40(8.1 \%)$ & $32(3 \%)$ & $72(4.6 \%)$ & \\
\hline MV pathology & & & & .001 \\
\hline Rheumatic & $102(21 \%)$ & $73(6.9 \%)$ & $175(11 \%)$ & \\
\hline Ischemic & $68(14 \%)$ & $126(12 \%)$ & $194(13 \%)$ & \\
\hline Myxomatous & $27(5.5 \%)$ & $117(11 \%)$ & $144(9.3 \%)$ & \\
\hline
\end{tabular}

$A F$, Atrial fibrillation; $A V$, aortic valve; $C H F$, congestive heart failure; COPD, chronic obstructive pulmonary disease; $L M S$, left main stem; $m$, meter; $M I$, myocardial infarction; $M V$, mitral valve; NS, not significant; $N Y H A$, New York Heart Association Functional Class; $P V D$, peripheral vascular disease; $S D$, standard deviation; $T I A$, transient ischemic attack.

LITA grafts, although uncommon in the whole study population, was less common in women than in men.

Aortic stenosis, aortic regurgitation, and mixed valvular disease were equally frequent in men and women. Bicuspid aortic valve disease was more common in men. Mechanical aortic valves were used in $23 \%$ of men and $17 \%$ of women. Biologic aortic valves were used in $75 \%$ of men and $79 \%$ of women. Aortic valve repair (reimplantation and remodeling) operations were performed in 33 patients. ${ }^{13,14}$
Mitral stenosis and mixed valve disease as well as rheumatic valve disease were significantly more common in women than in men. Myxomatous mitral disease was more common in men. Mitral valve repair was performed in $44 \%$ of men and $18 \%$ of women. Mitral valve replacement was more common in women. Biologic mitral valves were used in $40 \%$ of women and $28 \%$ of men. Mechanical mitral valves were used in the same proportion of men and women. 
TABLE 2. Operative variables of patients undergoing combined valve and coronary artery bypass grafting between January 1990 and October 2000 at the Toronto General Hospital

\begin{tabular}{|c|c|c|c|c|}
\hline Variable & Female & Male & Total & $P$ value \\
\hline Patients & $497(32 \%)$ & $1073(68 \%)$ & $1570(100 \%)$ & \\
\hline Priority of operation & & & & .013 \\
\hline Elective & $278(56 \%)$ & $680(63 \%)$ & $958(61 \%)$ & \\
\hline Urgent & $219(45 \%)$ & $393(36 \%)$ & $612(39 \%)$ & \\
\hline $\mathrm{CPB}(\overline{\mathrm{x}} \min \pm \mathrm{SD})$ & $129 \pm 3$ & $129 \pm 39$ & & NS \\
\hline Crossclamp time $(\bar{x} \min \pm S D)$ & $98 \pm 29$ & $100 \pm 30$ & & NS \\
\hline Distal grafts & & & & .001 \\
\hline$<3$ & $324(65 \%)$ & $591(56 \%)$ & $915(58 \%)$ & \\
\hline$\geq 3$ & $655(35 \%)$ & $482(44 \%)$ & $655(42 \%)$ & \\
\hline LITA grafts & $129(26 \%)$ & $436(41 \%)$ & $565(36 \%)$ & .001 \\
\hline AV surgery & & & & NS \\
\hline AV repair & $17(6 \%)$ & $16(2 \%)$ & $33(3 \%)$ & \\
\hline AV replacement & $258(94 \%)$ & $681(98 \%)$ & $939(97 \%)$ & \\
\hline MV surgery & & & & .001 \\
\hline MV repair & $32(18 \%)$ & $129(44 \%)$ & $161(34 \%)$ & \\
\hline MV replacement & $150(82 \%)$ & $167(56 \%)$ & $317(66 \%)$ & \\
\hline
\end{tabular}

$A V$, Aortic valve; $C P B$, cardiopulmonary bypass; $L I T A$, left internal thoracic artery; $M V$, mitral valve; $n s$, not significant; $S D$, standard deviation; $\bar{X}$, mean.

\section{Outcome}

Postoperative complications are shown in Table 3. Low cardiac output syndrome, the use of intra-aortic balloon pumping, incidence of leg infection, and requirement for permanent pacing were higher in women than men. There was no difference between the sexes in perioperative MI, postoperative stroke, renal failure, sepsis, or wound infection.

Overall hospital mortality was $7 \%$ in women and $4 \%$ in men $(P=.02)$. Analysis in different subgroups showed that mortality was highest in double and triple valves and CABG (9.8\%), followed by mitral valve and CABG (7.3\%), and lowest in aortic valve and CABG (3.4\%). When mitral valve repairs were excluded, overall hospital mortality was highest in the mitral valve replacement and CABG group $(10.62 \%, P=.001)$.

Over the 10-year period covered by this study, annual hospital mortality for all patients decreased from $6.8 \%$ in 1990 to $1.3 \%$ in 2000 . There was a trend of decreasing mortality in men $(6.9 \%$ to $0.9 \%)$. In women, in-hospital mortality was higher than in men and did not decrease significantly over the 10 years. Combined morbidity and mortality decreased significantly over the 10 -year period in men but not in women $(32 \%$ vs $21 \%, P=.002 ; 55 \%$ vs $38 \%, P=.21$ ).

Multivariable logistic analyses for morbidity and mortality are shown in Table 4 . The following risk factors were found to be independent risks of mortality: mitral valve replacement, age, LV dysfunction, NYHA classes III and IV, association of tricuspid valve disease, diabetes, peripheral vascular disease, and preoperative renal failure. Female gender was an independent risk factor for combined mortality and morbidity even when corrected for BSA.

\section{Discussion}

More men than women (2:1) underwent combined V/CABG procedures. The difference in rates of procedures is similar to that seen for CABG. This difference may reflect a difference in the incidence of disease and/or a lower rate of referral of women for the procedures. If the latter, fewer women may be referred because of a perceived high risk and poor outcome. Many studies, including those from our own institution, indicate that V/CABG operations are associated with a greater risk for early death than valve or CABG procedures alone. ${ }^{13-15}$ Table 5 gives the genderspecific mortality for isolated aortic, mitral, double valve, and CABG operations at our institution during the study period. Furthermore, our study demonstrates that operative mortality and morbidity after V/CABG is significantly higher in women than in men. In isolated CABG, these differences have been attributed by other investigators to differences in the demographic profile of women at the time of operation ${ }^{16-18}$ or to a referral bias. ${ }^{18-20}$ Women undergoing isolated CABG have more comorbid factors, such as diabetes and hypertension, and a smaller body size than men. ${ }^{20-22}$ In our study, this is also true for women undergoing V/CABG procedures. We found that women were older, smaller, and had more comorbid conditions such as hypertension, diabetes, transient ischemia attacks, and stroke. Similarly, more women than men required urgent or emergency operations with advanced NYHA functional class and congestive heart failure. These latter data suggest that the increase in morbidity and mortality may be related to late presentation, late referral, or both.

We did not see a difference in the number of diseased vessels, proportion of triple vessel disease, and left main 
TABLE 3. Postoperative complications of patients undergoing combined valve and coronary artery bypass grafting between January 1990 and October 2000 at the Toronto General Hospital

\begin{tabular}{|c|c|c|c|c|}
\hline Complication & Female & Male & Total & $P$ value \\
\hline $\mathrm{MI}$ & $13(2.6 \%)$ & $19(1.78 \%)$ & $32(2.0 \%)$ & NS \\
\hline LCOS & $84(17 \%)$ & $110(10 \%)$ & $194(12 \%)$ & .001 \\
\hline IABP & $45(9.1 \%)$ & $56(5.2 \%)$ & $101(6.4 \%)$ & .011 \\
\hline Stroke & $16(3.2 \%)$ & $35(3.2 \%)$ & $51(3.2 \%)$ & NS \\
\hline Renal function & $10(2.0 \%)$ & $21(2.0 \%)$ & $31(2.0 \%)$ & NS \\
\hline Infection leg & $17(3.4 \%)$ & $18(1.7 \%)$ & $35(2.2 \%)$ & .030 \\
\hline Permanent pacing & $45(9.1 \%)$ & $67(6.3 \%)$ & $112(7.1 \%)$ & .045 \\
\hline Hospital mortality & $18(7 \%)$ & $45(4 \%)$ & $79(5 \%)$ & .026 \\
\hline Combined morbidity and mortality & $192(39 \%)$ & $314(29 \%)$ & $506(32 \%)$ & .001 \\
\hline
\end{tabular}

IABP, Intra-aortic balloon pump; LCOS, low cardiac output syndrome; MI, myocardial infarction; NS, not significant.

TABLE 4. Multivariable analysis for mortality and morbidity of patients undergoing combined valve and coronary artery bypass grafting between January 1990 and October 2000 at the Toronto General Hospital

\begin{tabular}{lccc}
\hline Variable & $\begin{array}{c}\text { Upper } \\
\text { confidence } \\
\text { limit }\end{array}$ & Odds ratio & $\begin{array}{c}\text { Lower } \\
\text { confidence } \\
\text { limit }\end{array}$ \\
\hline Mitral valve replacement & 3.397 & 2.530 & 1.884 \\
Age & 1.037 & 1.023 & 1.009 \\
Female gender & 1.819 & 1.423 & 1.113 \\
Left ventricular dysfunction & 1.689 & 1.293 & 0.989 \\
NYHA class & 1.769 & 1.378 & 1.073 \\
Urgent operation & 2.581 & 1.773 & 1.218 \\
Number of diseased & 1.285 & 1.142 & 1.015 \\
$\quad$ vessels & & & \\
Reoperation & 4.660 & 3.032 & 1.973 \\
Aortic stenosis & 1.805 & 1.374 & 1.046 \\
Endocarditis & 8.444 & 3.025 & 1.084 \\
Hypertension & 1.574 & 1.249 & 0.990 \\
PVD & 1.870 & 1.353 & 0.979 \\
Renal failure & 5.242 & 2.739 & 1.431 \\
\hline
\end{tabular}

NYHA, New York Heart Association; PVD, peripheral vascular disease.

stem disease between women and men. Even though there were no differences in the number of diseased vessels between men and women, there were significant differences in the extent and type of revascularization. Only $35 \%$ of women had three or more grafts versus $44 \%$ of men. This may be incomplete revascularization for women or overrevascularization for men. The increased incidence of low cardiac output syndrome, use of postoperative IABP, and increased hospital mortality suggest it is incomplete revascularization for women.

Use of the LITA in men and women for V/CABG procedures was low for both men and women but more so for women. Other investigators have reported that use of the LITA graft in CABG does not increase morbidity and mortality and in some situations is associated with decreased mortality both in isolated CABG and in combined V/CABG procedures. ${ }^{6,23,24}$ The lower frequency of use of
TABLE 5. Gender-specific mortality for isolated aortic valve replacement, mitral valve replacement double valve replacement, and coronary artery bypass grafting between January 1990 and October 2000 at the Toronto General Hospital

\begin{tabular}{lcc}
\hline Procedure & Female (\%) & Male (\%) \\
\hline AVR & 2.3 & 1.7 \\
MVR & 3.3 & 2.2 \\
DTV & 8.8 & 4.6 \\
CABG & 3.6 & 1.6
\end{tabular}

$A V R$, Aortic valve replacement; $C A B G$, coronary artery bypass grafting; $D T V$, double, triple valve replacement; $M V R$, mitral valve replacement.

the LITA graft in our study may have contributed to the increased mortality in women and may reflect an institutional bias. Since we intended this study to be a prognostic tool for patients undergoing combined V/CABG, all process of care variables including LITA use were not included in the survival statistical model.

Mitral valve replacement appears to be an independent risk factor for morbidity and mortality in V/CABG operations. Other investigators have reported that mortality in combined mitral valve and CABG surgery is higher for women than men. ${ }^{25}$ In our study, women underwent mitral valve replacements more often than men. This is most likely related to the etiology of the valve disease. In our study, severe mitral stenosis and mixed valve disease as well as rheumatic valve disease were significantly more common in women than men. Myxomatous mitral disease was more common in men. It is known that rheumatic mitral stenosis is less amenable to repair than myxomatous mitral regurgitation and that operative mortality is lower after mitral valve repair than after replacement. ${ }^{26}$ These findings may explain why a significantly smaller number of women underwent mitral valve repair as well as some of the differences in mortality.

In our study, female gender was an independent predictor for increased combined morbidity and mortality. Aranki and 
coworkers $^{27}$ also reported that female gender was a significant predictor of operative mortality in the concomitant aortic valve replacement/CABG group but not in the isolated aortic valve replacement group. In previous reports from our unit and others, ${ }^{28,29}$ gender was not found to be an independent risk factor in isolated valve replacement. Unpublished data from our unit suggests that female gender is an independent predictor for isolated CABG. These data suggest that the differences in morbidity and mortality in women and men in V/CABG operation may be related to the coronary artery disease and its associated comorbid conditions.

\section{Conclusions}

It is apparent that there are differences in morbidity and mortality after combined V/CABG procedures for men and women.

We found that female gender is an independent risk factor for increased morbidity and mortality. It is not clear whether the differences are due to sex-related differences in the biology of the disease or in gender-related issues of treatment and access to care. Further investigation is merited. In addition, perhaps it is time to acknowledge and embrace the concept that there are differences between the genders and to develop a separate and distinct analysis of mortality and morbidity risks in women. Until this occurs, careful consideration should be given to the true risks and benefits of $\mathrm{V} / \mathrm{CABG}$ for women.

We are grateful to May Farquhar for her administrative assistance and we thank the cardiac surgeons of the Division of Cardiovascular Surgery, Toronto General Hospital, University Health Network for allowing us to review and report their results.

\section{References}

1. He GW, Hughes CF, McCaughan B, Thombson DS, Leckie BD, Yang $\mathrm{CQ}$, et al. Mitral valve replacement combined with coronary artery operation: determinants of early and late results. Ann Thorac Surg. 1991;51:916-23.

2. Lytle BW, Cosgrove DM, Gill CC, Stewart RW, Golding LAR, Goormastic M, et al. Mitral valve replacement combined with myocardial revascularization: early and late results for 300 patients, 1970 to 1983. Circulation. 1985;71:1179-85.

3. Garcia Andrade I, Cartier R, Panisi P, Ennabli K, Grondin CM. Factors influencing early and late survival in patients with combined mitral valve replacement and myocardial revascularization and in those with isolated replacement. Ann Thorac Surg. 1987;44:607-13.

4. Thourani VH, Weintraub WS, Craver JM, Jones EL, Gott JP, Brown WM III, et al. Influence of concomitant CABG and urgent/emergent status on mitral replacement surgery. Ann Thorac Surg. 2000;70:778-84.

5. Ashraf SS, Shaukat N, Odom N, Keenan D, Grotte G. Early and late results following coronary bypass surgery and mitral valve replacement. Eur J Cardiothorac Surg. 1994;8:57-62.

6. Gall S Jr, Lowe JE, Wolfe WG, Oldham HN Jr, Trigt PV III, Glower DD. Efficacy of the internal mammary artery in combined aortic valve replacement-coronary artery bypass grafting. Ann Thorac Surg. 2000;69:524-30.

7. Magovern JA, Pennock JL, Campbell DB, Pae WE, Bartholomew M, Pierce WS, et al. Aortic valve replacement and combined aortic valve replacement and coronary artery bypass grafting: predicting high risk groups. J Am Coll Cardiol.. 1987;9:38-43.

8. Abramov D, Tamariz MG, Sever JY, Christakis GT, Gopal BG,
Heenan AL, et al. The influence of gender on the outcome of coronary artery bypass surgery. Ann Thorac Surg. 2000;70:800-6.

9. Mickleborough LL, Takagi Y, Maruyama H, Sun Z, Mohamed S. Is sex a factor in determining operative risk for aortocoronary bypass graft surgery? Circulation. 1995;92(Suppl II):II80-4.

10. Weintraub WS, Wenger NK, Jones EL, Craver JM, Guyton RA. Changing clinical characteristics of coronary surgery patients: differences between men and women. Circulation. 1993;88:79-86.

11. Rahimtoola SH, Bennett AJ, Grunkemeier GL, Block P, Starr A. Survival at 15 to 18 years after coronary bypass surgery for angina in women. Circulation. 1993;88:71-8.

12. Ivanov J, Tu JV, Naylor CD. Ready-made, recalibrated, remodeled? Issues in the use of risk indices for assessing mortality after coronary artery bypass graft surgery. Circulation. 1999;99:2098-104.

13. Parsonnet V, Lean D, Bernstein AD. A method of uniform stratification of risk for evaluating the results of surgery in acquired adult heart disease. Circulation. 1989;79(Suppl 1):3-12.

14. Hannan EL, Kilburn H, O'Donnell JF, Lukacik G, Sheilds EP. Adult open heart surgery in New York state. An analysis of risk factors and hospital mortality rates. JAMA. 1990;264:2768-74.

15. Tuman KJ, McCarthy RJ, March RJ, Najafi H, Ivankovich AD. Morbidity and duration of ICU stay after cardiac surgery. A model for preoperative risk assessment. Chest. 1992;102:36-44.

16. Christakis GT, Weisel RD, Buth KJ, Fremes SE, Rao V, Panagiotopoulos KP, et al. Is body size the cause for poor outcomes of coronary artery bypass operations in women? J Thorac Cardiovasc Surg. 1995; 110:1344-58.

17. O'Connor GT, Morton JR, Diehl MJ, Olmstead EM, Coffin LH, Levy DG, et al. Differences between men and women in hospital mortality associated with coronary artery bypass graft surgery. The Northern New England Cardiovascular Disease Study Group. Circulation. 1993; 88(5 Pt 1):2104-10.

18. Khan SS, Nessim S, Gray R, Czer LS, Chaux A, Matloff J. Increased mortality of women in coronary artery bypass surgery: evidence for referral bias. Ann Intern Med. 1990;112:561-7.

19. Tobin JN, Wassertheil-Smoller S, Wexler JP, Steingart RM, Budner N, Lense L, et al. Sex bias in considering coronary bypass surgery. Ann Intern Med. 1987;107:19-25.

20. Naylor CD, Levinton CM. Sex-related differences in coronary revascularization practice: the perspective from a Canadian queue management. Can Med Assoc J. 1993;149:965-73.

21. Christakis GT, Ivanov J, Weisel RD, Birnbaum PL, David TE, Salerno TA. The changing pattern of coronary artery bypass surgery. Circulation. 1989;80(Suppl I):I151-61.

22. Fisher LD, Kennedy JW, Davis KB, Maynard C, Fritz JK, Kaiser G, et al. Association of sex, physical size, and operative mortality after coronary artery bypass in the Coronary Artery Surgery Study (CASS). J Thorac Cardiovasc Surg. 1982;84:334-41.

23. Cosgrove DM, Loop FD, Lytle BW, Coormastic M, Stewart RW, Gill $\mathrm{CC}$, et al. Does mammary artery grafting increase surgical risk? Circulation. 1985;72(Suppl II):II170-4.

24. Kirklin JW, Naftel DC, Blackstone EH, Pohest GM. Summary of a consensus concerning death and ischemic events after coronary artery bypass grafting. Circulation. 1989;79(Suppl I):I81-91.

25. Kirklin JK, Naftel NC, Blackstone EH, Kirklin JW, Brown RC. Risk factors for mortality after primary combined valvular and coronary artery surgery. Circulation. 1989;79(Suppl I):I185-90.

26. Enriquez-Sarano M, Schaff HV, Orszulak TA, Tajik TA, Bailey KR, Frye RL. Valve repair improves the outcome of surgery for mitral regurgitation. A multivariate analysis. Circulation. 1995;91:1022-8.

27. Aranki SF, Rizzo RJ, Couper CS, Adams DH, Collins JJ Jr, Gilden JS, et al. Aortic valve replacement in the elderly. Effect of gender and coronary artery disease on operative mortality. Circulation. 1993; 88(Suppl II):II17-23.

28. Christakis GT, Weisel RD, David TE, Salerno TA, Ivanov J. Predictors of operative survival after valve replacement. Circulation. 1988;78:125-34.

29. Turina J, Stark T, Seifert B, Turina M. Predictors of long-term outcome after combined aortic and mitral valve surgery. Circulation. 1999;100(Suppl 19):II48-53. 